\title{
Axiological Worldview of the Tajik Young People: Modern Values
}

\author{
Diloro Iskandarova ${ }^{1 *}$, Olga Ladygina ${ }^{2}$, \\ ${ }^{1}$ Faculty of Philology, Russian-Tajik Slavonic University, 30 M. Tursunzoda St., Dushanbe, 734025, Tajikistan \\ ${ }^{2}$ Faculty of History and International Relations, Russian-Tajik Slavonic University, 30 M. Tursunzoda St., Dushanbe, 734025 , \\ Tajikistan
}

\begin{abstract}
The axiological worldview of modern society may be described through a language. It is the language being a 'tool' of human consciousness and thinking that provides access to deep structures of consciousness. The axiological category of consciousness is also one of the key components of linguistic personality. Taking into account the relevance of the study devoted to axiological worldview of the Tajik society and values typical for modern young population, the study is based on a free association experiment conducted to reveal axiological dominants in language consciousness of Tajik young population. Students of the Russian-Tajik Slavonic University (RTSU) aged from 16 to 25 participated in the experiment. The choice of this age group to study axiological dominants made it possible to identify and analyze universal and modern values of the younger generation. The paper describes the results of the study covering modern values within the association consciousness of young people in Tajikistan.
\end{abstract}

\section{Introduction}

In linguistics the analysis of axiological preferences opens possibilities to study the national linguistic consciousness and to create the model of linguistic identity. The language fixes and reflects the system of values, attitudes, opinions of a certain society. All these combined may be called the axiological worldview.

The axiological worldview being one of the aspects of the human mindset is defined as the characteristic of the system of ideals guiding a person towards his preferences, objectives, motives and acts. The dominating values define what is the most important and significant in life of every individual. At the level of a social group there are certain accepted values shared by other people and unaccepted values which do not need any approval to follow them. However, the axiological dominants change over time in culture and in the human mindset. What was considered valuable in the last century may be irrelevant these days. This is explained by the fact that social, economic and political changes within a society may directly change the initial hierarchy of values in axiological system or introduce new values meeting the demands of a modern individual.

The axiological worldview includes the most critical meanings and valuable dominants, the combination of which forms a certain type of culture supported and maintained within a language. Besides, within one language culture this concept represents a non-uniform formation since different social groups may have diverse values. At the same time, the axiological worldview is present both in collective and individual consciousness.

\subsection{Importance of the Problem}

The language being the most amazing and at the same time the most sophisticated manifestation of a human, provides a person with linguistic means to produce diverse assessment of objects and phenomena of the reality. It is the language that creates, maintains and transfers values thus forming a unique axiological sphere within linguoculture of a certain nation. It is important to study axiological fundamentals of national linguistic consciousness, to create the model of a valuable system, to reveal national features within the axiological sphere of linguistic consciousness of Tajik young population.

The linguistic axiological study of value-based dominants of young people at the age between 16-25 years will make possible to reveal aspirations, interests, desires and objectives of modern young generation. The younger population constitutes that part of society, from which the society expects the most initiatives, development, improvements and changes.

\subsection{Purpose of the Study}

The purpose of this study is to analyze the values of young population of Tajikistan. The study in the field of various aspects of association consciousness is triggered in Tajikistan by the research group from the RussianTajik Slavonic University led by one of the authors of this paper within the project 'Cognitive and ethnopsycholinguistic study of the problems of tolerance and interethnic communications' (2015-2016). The study covered the issues related to ethnic stereotypes, sources

\footnotetext{
*Corresponding author: iskandarova@ hotmail.com
} 
of intolerance in the society, national identity [1]. This study was continued and resulted in the understanding that these aspects are closely linked to problems of linguistic discrimination [2]. However, it turned out that the problems related to the above aspects are also associated with axiological worldview. The study caused the need to identify the values of young population of Tajikistan forming the basis of their mindset.

\subsection{Methodological Framework}

The study was based on axiological concepts and theories developed in works by N.D. Arutyunova [3], E.M. Wolf [4], A.N. Baranov [5], G.F. Gibatov [6], G.Ya. Golovnykh [7], A.A. Ivin [8], V.I. Karasik [9,10], D.A. Leontyev [11], N. Zerkina, basic concepts described by Samuel L. Hart [13] and others [14].

The main methods of this study included the free association experiment, a descriptive method, a method of analysis and synthesis.

The free association experiment is an efficient method used to identify verbal associations, which give information on deep structures of linguistic consciousness. The free association experiment is based on the following principle: to the stimulus word (S) the respondents answer with words-reactions (R) coming to their mind first, at the same time the experimenter does not limit the respondents to neither formal nor semantic features of words-reactions.

The empirical data obtained during the experiment were classified and divided into the following groups: paradigmatic responses, syntagmatic responses, phrases, sentences, clichés (set phrases, sentences) and responses reflecting a proverb or a saying. In case of syntagmatic associations their grammatical class does not coincide with a stimulus word, such associations are always found in predicative relations. For example, $\mathrm{S}$ education $-\mathrm{R}$ higher, $\mathrm{S}$ career $-\mathrm{R}$ important. The associations, where words-reactions represent the same grammatical class as stimulus words, are called paradigmatic. For example, S education $-\mathrm{R}$ mind, $\mathrm{S}$ career $-\mathrm{R}$ money.

The next stage to study axiological dominants included the analysis of reactions to detect special characteristics of universal and modern values of young people. There was also an attempt to identify reactions to a stimulus word having the (positive or negative) assessment nature if those were present in answers of respondents. The value analysis resulted in the general calculation of the number of reactions to a stimulus word and identification of the ratio of single and non- single responses.

During the association experiment, the respondents were in total offered 16 values, of which 8 were universal (basic) values, such as family, health, friends, love, belief (religion), honesty, respect for adults and kindness. The other 8 values represented the values of modern society: career, money, wealth, visual appeal, education, tolerance, independence and success.

During the association experiment, the respondents were given a task to write the first associations coming to their mind regarding the stimulus values. The respondents had 10 minutes to complete the task alongside with an opportunity to give several associations to one stimulus.

The paper considers only a few associations with modern values of the young population.

\section{Results and Discussion. Modern values of Tajik young people}

\subsection{Value Education}

In recent years the value and understanding of education by modern young people has changed considerably compared to education of the Soviet period. Education became an integral part of the development of a 'stable' person in the period of unstable tenor of life within the modern society and the entire world. The public need in qualified specialists poses a demand to modern people in certain knowledge, skills and abilities necessary for professional or production activity. It is much quicker and easier for an educated person in present unstable society to adapt to social or political changes of public life. Besides, the quality of human life directly depends on education. It is no wonder that realizing this phenomenon the younger generation strives for education in order to ensure stability and confidence in the future.

The study of the value of education revealed that young people emphasize the high importance and need to get education through reactions: important 4, the most important 2, needed, the most necessary 2, everyone shall have it 3, compulsory 2, highly-demanded and responsibility. First of all, a person seeks to get education to develop himself and become intelligent (to develop as an individual, to develop erudition, sense, mind, to foster brain development). According to definitions given by respondents, education is characterized as high 19, average, normal, good and excellent. It is no wonder that students numerous times wrote high to the stimulus education since at this stage of their life they want to get higher education. There were reactions caused by the educational process: study 4 , knowledge 2, RTSU 2, university 2, associate professor, school and reading. Young people associate education with future success and a diploma (to have a diploma), as well as with pride and reputation of a person. One respondent expressed the concern with low level of education in the city.

The analysis of responses to a stimulus word revealed the following paradigmatic reactions: study, mind, work, knowledge, RTSU, university, career, person, associate professor, responsibility, erudition, pride, self-improvement, glory, reading, sense, school, future; syntagmatic reactions: high, important, necessary, needed, average, compulsory, normal, highlydemanded, good, excellent; reactions-phrases: the most important, the most necessary, urgent career, development of an individual, mental development, further success, to have a diploma, without tyrant teachers; reactions-sentences: everyone shall have it; low level of education in the city; brain development.

According to the degree of frequence, the association field of a stimulus word education is presented by 
frequency answers: high 19, (the most important 2) important 6, (the most necessary 2, necessary 1) necessary 5, study 4, mind 6, everyone shall have it 3, work 3, knowledge 2, RTSU 2, university 2, (successful) career 2, compulsory 2; and single answers: average, person, associate professor, normal, development of an individual, responsibility, erudition, low level of education in the city, pride, self-improvement, glory, mental development, reading, sense, school, further success, to have a diploma, future, brain development, highly-demanded, good, excellent, without tyrant teachers.

The total number of reactions to education made 177 , single answers - $23(13 \%)$, non-single answers - 154 $(87 \%)$.

\subsection{Value Wealth}

A person is actively involved in creation, accumulation and storage of wealth. People believe that wealth is very important and valuable. However, the definition of wealth is ambiguous since each person defines wealth and its place within the axiological worldview in a certain manner. Despite the individual nature of defining wealth, a person lives in a society, which automatically influences all members of this society thus 'forcing' them to adhere to a certain uniformity of views thereby ensuring the integration of society. Hence, the interaction of people within one environment leads to a relatively common idea of value and importance of wealth in human livelihood. Having defined and revealed the meaning of wealth in people linguoculture, what is its importance and how this wealth is reached, it is possible to draw a major conclusion on the human values for future development.

The analysis of students' reactions to a stimulus word wealth deminstrated that young people associate wealth with material and non-material benefits. Such universal values as family 13, happiness 8 , health 7 , relatives 2 (when the family is close), parents, love, respect, friends, family, mother and child are considered non-material benefits. Material benefits include money 12, resources, property, necessary things, luxury and house, which can be deserved and earned through work (several years of work, earn). It is better to have a moderate wealth, which brings peace. According to respondents, the wealth is achievement, authority and career of a person, as well as a source of security, success and power. The respondents believe that one cannot always be rich (passes away), that wealth does not depend on money and is not important in human life (not so important, nothing) and it sometimes cases evil and enemies. At the same time, wealth gives the feeling of satisfaction and full value of life (I made it in life).

Thus, the answers of respondents revealed the following paradigmatic reactions: family, money, happiness, health, work, book, relatives, parents, love, security, respect, resources, friends, success, need, enemies, family, mother, property, house, luxury, achievement, child, career, evil, authority; syntagmatic reactions: to work, earn, not important, moderate, oh, yes!, necessary, nothing; reactions-phrases: several years of work, it is possible to earn, not so important, I will be rich, to have everything, necessary things, does not depend on money, I made it in life, peace, passes; reactions-sentences: when you have a good girl; when your family is close; it is not always possible to be rich; it is a pity that wealth is the main thing for people.

According to the degree of frequence, the association field of a stimulus word wealth is presented by frequency reactions: family 13, money 12, happiness 8 , health 7, (work 1, several years 1) of work 3, (earn) it is possible to earn 2, book 2 when you have a good girl 2, (when your family is close) relatives 2 , parents 2 , love 2 , security, respect 2, 2 (not so important) not important; and single reactions: I will be rich, to have everything, necessary things, does not depend on money, it is not always possible to be rich, resources, friends, moderate, oh, yes!, success, need, it is a pity that wealth is the main thing for people, enemies, family, it is necessary, mother, property, nothing, house, luxury, I made it in life, power, peace, achievement, child, career, evil, passes, authority.

The total number of reactions to wealth made 91 , single answers - $30(33 \%)$, non-single answers - 61 $(67 \%)$.

\subsection{Value Career}

In modern society, besides personal relations with members of a society, a person has social and production relations with representatives of this society. It means that the person is actively involved in professional activity, which gives an opportunity to use exceptional talents, skills and knowledge in practice. Work does not only provide professional environment for application and development of professional strengths of a person but stimulates and motivates a person for the upward move in the so-called 'career ladder'. In the 21 st century the career became an absolutely new and relevant value. Young, educated and ambitious people spend more time, energy and efforts to achieve social heights. Successful career typifies one of the images of this social height.

A linguistic consciousness of a person can answer the question whether a career is important for modern Tajik young population. Lexemes used by people in linguistic consciousness can characterize, assess or give an idea with regard to surrounding reality. Thus, the free association experiment revealed that the participants of the study representing students of RTSU of various specialties understand the career as means of achieving the material and non-material benefits. They consider money 11, personal business 4, company, wealth and material security as material benefits. Career brings nonmaterial benefits in the form of success 4 , respect 3 , achievement, experience, development, self-realization, self-development and status. Career, as realized by young people, shall be successful and tremendous 2, but such career is reached only though human labor 4, diligence and hard work. The career takes place and exists in professional activity of a person (favourite profession, lawyer 2, management, manager, bank director). For some respondents a career is the objective of their life (to pursue an ambition, something we strive for), which they connect with hopes for the future (in the future 2, Insha'Allah 2, no, but it will come later). To make and achieve a career means growth over the years 
for young people, to be the best and to achieve the best. Besides, a person building a career has an opportunity to use the gained knowledge in career and to help people.

The opinions of respondents regarding the importance of a career in life were ambiguous. The high importance of a career is given in such reactions as it is necessary, needed, the most important, number one, while the low importance is found in such answers as $a$ little bit important 2, nonsense, not the main thing in life.

Thus, the answers of respondents revealed the following paradigmatic reactions: money, business, purpose, diligence, work, success, successfulness, respect, lawyer, achievement, work, experience, management, manager, development, girl, selfrealization, independence, nonsense, dream, company, status, wealth, benefit; syntagmatic reactions: in the future, it is necessary, needed, tremendous, successful, do, I think; reactions-phrases: personal business, Insha'Allah, a little bit important, to be the best, the most important, bank director, self-development, growth over the years, favourite profession, material security, help, not the main thing in life, to achieve the best, to pursue the ambition, number one; reactions-sentences: no, but it will come later; all efforts and work of a person; to use the gained knowledge in career; what we strive for.

According to the degree of frequence, the association field of a stimulus word career is presented by frequency reactions: money 11, (personal 1) business 4, purpose 4, (diligence 1) work 4, (successfulness 1) success 4, respect 3, Insha'Allah 2, it is a little bit important 2, in the future 2, it (is necessary) needed 2, lawyer 2, achievement 2, tremendous 2, work 2 and single reactions: successful, experience, to be the best, management, manager, no, but it will come later, do, development, all efforts and work of a person, to use the gained knowledge in career, girl, self-realization, the most important, I think, independence, bank director, nonsense, self-development, dream, growth over the years, favourite profession, company, status, wealth, material security, help, benefit, not the main thing in life, to achieve the best, to pursue the ambition, number one, what we strive for.

The total number of reactions to career made 80 , single answers - 34 (43\%), non-single answers - 46 $(57 \%)$.

\subsection{Value Success}

Success is another value of modern people. Success is quite often treated ambiguously. This ambiguity is caused by the fact that various people have different understanding of success, including certain, separate, and small achievements in various spheres of human life. It depends on the hierarchy of human values and on what priorities does the person set in life. For example, if an individual wants to get a well-paid job, then he/she will study hard and will seek to obtain a prestigious diploma in a reputable educational institution, which will further demonstrate his/her interest in sound academic background. Or, if a person wants to have a close-knit family, to raise children of education and culture, he/she will direct time, resources, efforts and thoughts towards family harmony. In such cases a person with a good job or happy family would be right to consider himself a successful person. The given examples indicate subjective human perception of success. Nevertheless, the modern society defined the common set of criteria illustrating human success. This set of success criteria was observed in reactions of respondents during the free association experiment.

Thus, modern young people of Tajikistan associate success with success in career 6, societal impact 2, money 2, position, social status, wealth, business, work and profession (to be a good professional). These associations may constitute the social success. However, such reactions as family 2, happiness, mother and home illustrate the fact that success is also achieved in private life. The majority of respondents were in one mind regarding the fact that a person becomes successful as a result of certain efforts (to achieve success, to study and work a lot, set targets and try to achieve them), endeavors (to try 2, aspiration, result of diligence), work (work 2, diligence, years of work), self-development (experience, good mind, clever brain, since childhood) and personal features (confidence 2, ability, activity, mind). At times the success is achieved as a result of good luck and fortune. Young people emphasize the importance of being successful in life in the following reactions: it is necessary 2, compulsory, yes, the best in life and of course. Generally, it may be concluded that the attitude of modern young people to the value of success is characterized as the purpose bringing material and 'spiritual' benefit and which shall be achieved in the future.

Thus, the answers of respondents revealed the following paradigmatic reactions: career, in career, diligence, work, confidence, family, money, influence, desire, aspiration, position, in life, in business, mother, wealth, happiness, since childhood, ability, strategy, chance, luck, mind, experience, home, work, benefit, purpose, activity; syntagmatic reactions: no, it is necessary, to try, it will be, in everything, surely yes, of course, average, personal; reactions-phrases: selfconfidence, family success, influence in society, years of work, to study and work a lot, a result of diligence, the best in life, status in society, to achieve success, set targets and try to achieve them, good mind, clever brain; reactions-sentences: it is not always possible to be successful; to be a good professional; I have no progress yet.

According to the degree of frequence, the association field of a stimulus word success is presented by frequency answers: (in career 1) career 6 , (diligence 1) work 3, no 2, it is necessary 2, (in itself 1) confidence 2, to try 2, (family success) family 2, (in society) influence 2, money 2; and single answers: years of work, desire, aspiration, will be, position, to study and work a lot, in life, in everything, of course, yes, a result of diligence, it is not always possible to be successful, the best in life, in business, naturally, mother, wealth, happiness, to be a good professional, I have no progress yet, average, status in society, since childhood, ability, strategy, to achieve success, good luck, set targets and try to achieve them, luck, mind, experience, personal, good mind, home, work, benefit, purpose, activity, clever brain. 
The total number of reactions to success made 62 , single answers - $39(63 \%)$, non-single answers - 23 (37\%).

\section{Conclusion}

The analysis of modern values within axiological system of young people reveals the majority of reactions to education 177, wealth 91 and career 80. The bigger number of reactions ensures high ratio of non-single answers, which illustrates high uniformity of ideas among young people regarding such values as education, wealth and career.

Modern young people set a high value on education in life and seek to get it. The importance of getting higher education, which develops mental abilities of a person, is a key to successful career and material wealth. Young people more and more reject the previously common idea to get higher education for the sake of a diploma. They wish to gain solid and good knowledge. The current tendency of the labor market is focused on highly-qualified and competent workers, which is a necessary element towards competitiveness in any business domain.

Within the linguistic consciousness of respondents the value of wealth is associated, first of all, with such universal values as family, health, parents, happiness, love, respect, which demonstrates high standards of young people and their desire to acquire supreme values of human life, which do not depend on money.

In their pursuit for education the contemporary young people want to reach and build their future successful career. According to them, a career serves as means of achieving the social status (respect, influence, status, image, material wealth, etc.), which are presented by material and non-material benefits. At the same time the young generation realizes that in the modern world the successful career is only achieved through hard work, knowledge and diligence of a person.

The young people associate success with achievements in career, money, social influence and status. The person achieves success through selfdevelopment, abilities, mind and activity, which implies work and efforts towards the achievement of success in any sphere of human life.

Thus, the analysis of modern values of Tajik young population made it possible to conclude that young people are socially active, well-focused in their aspirations, wish to achieve success, influence and status in the society through education, material wealth and career.

The obtained results will provide for better understanding of values shared by young generation and will allow taking measures to control and solve potential spiritual and moral problems since it is critical for the wellbeing of the society and for the future of the country in general.

\section{Acknowledgements}

The authors express their gratitude to the Russian-Tajik (Slavonic) University for financing the research under the University Development Program for 2018.

\section{References}

1. D.M. Iskandarova, O.V. Ladygina, N.N. Salikhov, H.D. Shambezoda, M.B. Davlatmirova, Social and Linguistic Aspects of the Tajik National Identity Formation: Findings of the Survey of Students in Tajikistan. Indian Journal of Sciences and Technology, 9(5), 1-13 (2016) DOI: 10.17485/ijst/2016/v9i5/87594 Retrieved from: http://www.indjst.org/index.php/indjst/article/downlo ad/87594/67222

2. D. Iskandarova, O. Ladygina, K. Shambezoda, A. Zolotukhin, V. Abdukhamitov, Problems of linguistic discrimination in the communicative space of Tajikistan: legal, sociolinguistic and educational aspects, Journal of Social Studies Education Research, 8(3), 168-189 (2017) Retrieved from: http://jsser.org/article/view/5000213983

3. N.D. Arutyunova, Language and world of a person. (Moscow, Languages of the Russian culture, 1999)

4. E.M. Wolf, Functional semantics of assessment. (Moscow, USSR editorial, 2002)

5. A.N. Baranov, Axiological strategy in language structure (paremiology and lexicon), Aspects of linguistics, 3, 74-90 (1989)

6. G.F. Gibatova, Axiology in language, Bulletin of Orenburg State University, 2(121), 127-131 (2011)

7. G.Ya. Golovnykh, Valuable orientations and reorganization of public consciousness, Philosophic sciences, 6, 85-86 (1989)

8. A.A. Ivin, Axiology (M.: Higher school, 2006)

9. V.I. Karasik, Language, circle: individual, concepts, discourse (Volgograd: Peremena, 2002)

10. V.I. Karasik, Axiological linguistics: concepts and discourse, Germanic studies in Russia. Traditions and prospects (Novosibirsk: NSU publishing house, 2004)

11. D.A. Leontyev, Valuable orientations, Person. Philosophical and encyclopedic dictionary (Moscow, 2000)

12. N. Zerkina. , et al. Axiological linguistics and foreign language teaching - Procedia - Social and Behavioral Sciences, 199, 254 - 260 (2015) Retrieved from: https://www.sciencedirect.com/science/article/pii/S1 $\underline{877042815045255}$

13. L. Hart Samuel, Axiology. Theory of Values. Philosophy and Phenomenological Research, 32, 1, 29-41 (1971)

14. Axiology Retrieved from: https://www.britannica.com/topic/axiology. 